\title{
JUVENILE IDIOPATHIC ARTHRITIS ASSOCIATED WITH INCOMPLETE PRIMARY HYPERTROPHIC OSTEOARTHROPATHY (PACHYDERMOPERIOSTOSIS)
}

\author{
Vasilia Cristina Iorgoveanu ${ }^{1}$, Raluca Ionescu ${ }^{1}$, Laura Groseanu ${ }^{1,2}$, Ruxandra Ionescu ${ }^{1,2}$ \\ ${ }^{1}$ Department of Internal Medicine and Rheumatology, Sf. Maria Clinical Hospital, Bucharest, RCRD \\ ${ }^{2}$ Carol Davila University of Medicine and Pharmacy, Bucharest
}

Mention: Vasilia Cristina Iorgoveanu and Raluca Ionescu had an equal contribution in editing the present paper.

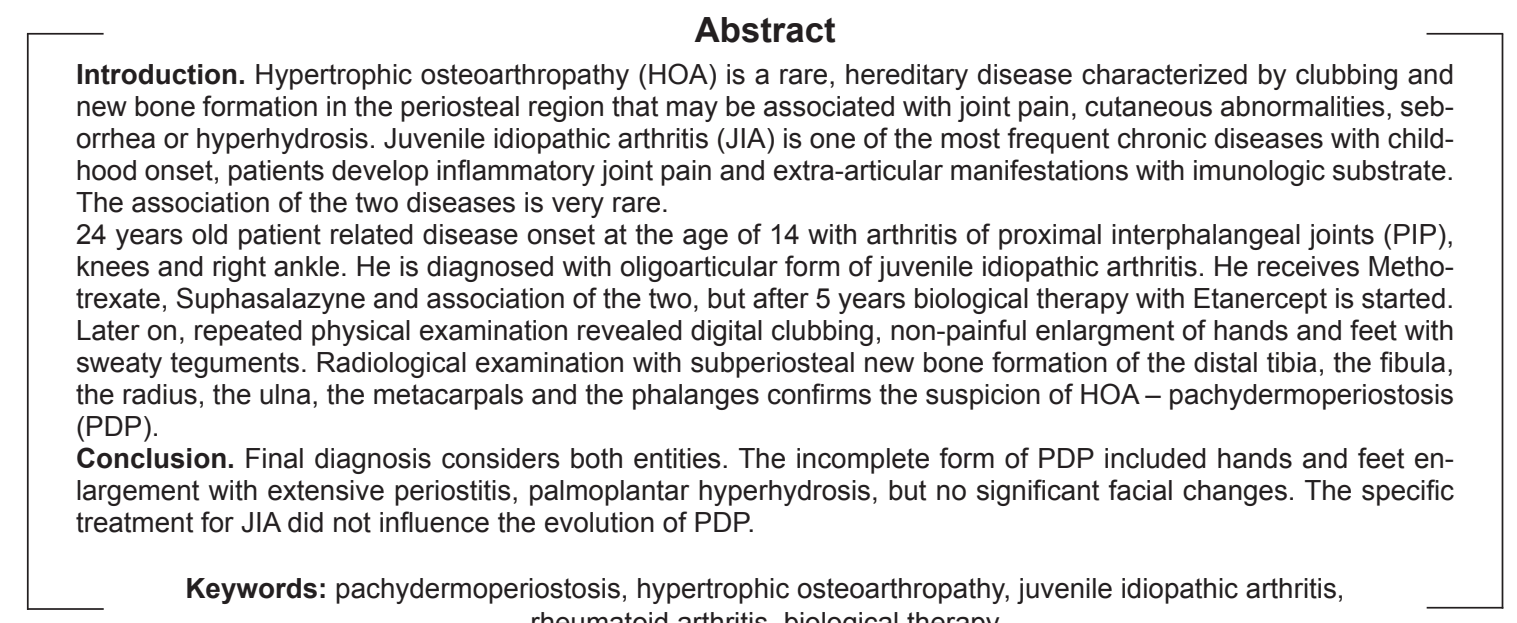

Keywords: pachydermoperiostosis, hypertrophic osteoarthropathy, juvenile idiopathic arthritis, rheumatoid arthritis, biological therapy

\section{INTRODUCTION}

Pachydermoperiostosis (PDP), primary hypertrophic osteoarthropathy (HOA) or Touraine-SolenteGolé syndrome is a rare genetic disease with both autosomal dominant and recessive inheritance, with various levels of penetration. The autosomal dominant inheritance is associated with the incomplete form, while the recessive form is associated with the complete form with poorer prognosis. PDP represents only $5 \%$ of HOA, the majority being secondary forms related to cardiovascular or malignant pathologies. The primary form favors the Afro-American race, and the male: female ratio is 7:1 (1). The typical age of onset is late childhood or adolescence with a gradual progression and auto limitation after approximately 5 years of evolution.

\section{CASE PRESENTATION}

24 years old patient related insidious disease onset at the age of 14 (august 2005) with arthritis in $2^{\text {nd }}-5^{\text {th }}$ bilateral proximal interphalangeal (PIP) joints, knees and right ankle joint. Lab examinations at that time revealed mild inflammatory syndrome $(\mathrm{ESR}=40 \mathrm{~mm} / \mathrm{h}, \mathrm{CRP}=28 \mathrm{mg} / \mathrm{l})$, negative rheumatoid factor, negative antinuclear antibodies and negative for HLAB27. After a couple of months, he is finally diagnosed with juvenile idiopathic arthritis, therefore the patient is recommended treatment with Sulphasalazine (SSZ) up to 2,5 g per day in association with NSAIDS. This treatment plan is followed for 2 years, during which he presents with multiple episodes of arthritis. Consecutively, Methotrexate 
(MTX) is added, but with scarse results. Therefore, in 2008, when he is transferred to an adult rheumatology clinic, biological therapy is started with Etanercept (ETN) $25 \mathrm{mg}$ twice a week in association with Methotrexate. He soon reached clinical and biological remission, sustained since 2010 .

Since the age of 16 , at the physical examination, clubbing of the fingers, diffuse hand and feet swelling and enlargement (Figure 1, Figure 2) were noticed. The skin of the face was a little greasy and thickened but without major facial changes. He also reported excessive perspiration, erectile dysfunction. The father and the grandfather of the patient were very tall and had similar swelling of the fingers and toes, but never been investigated.

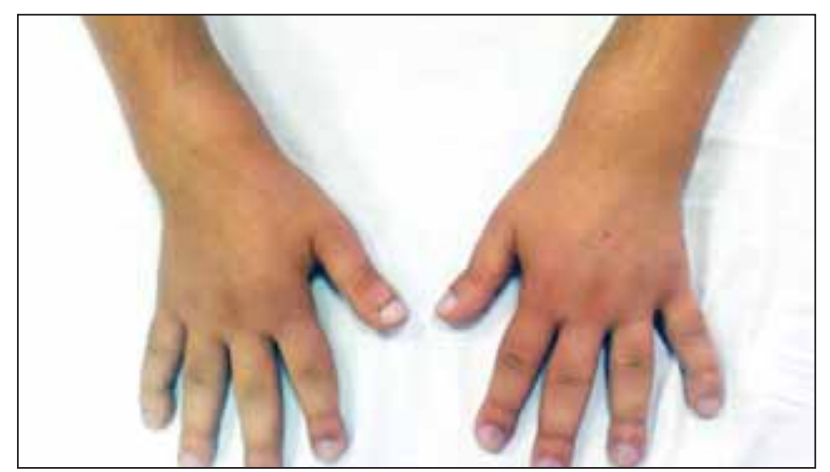

FIGURE 1. Clinical examination of hands

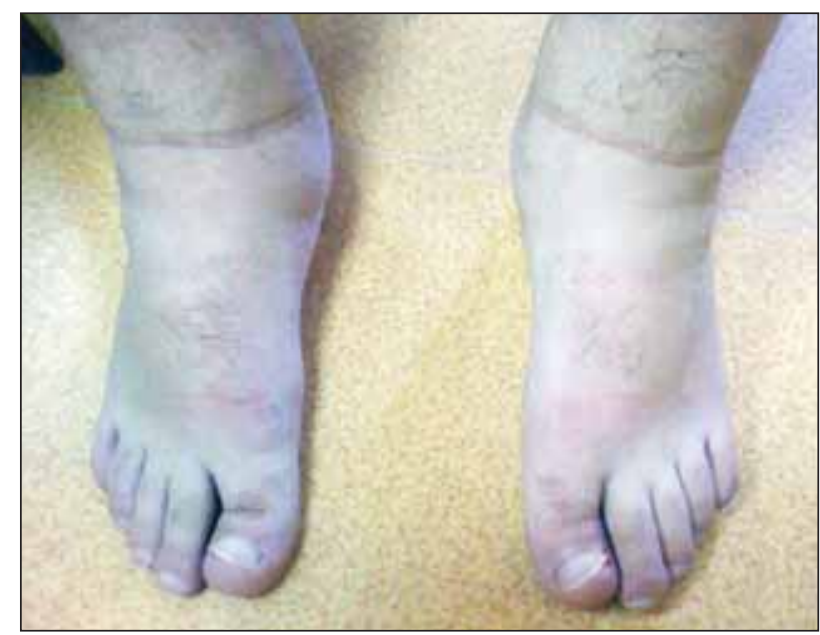

FIGURE 2. Clinical examination of feet

Radiological investigation of both arms and legs reveal bilateral extensive irregular periosteal reaction of the radius and ulna with diffuse soft tissue swelling; same changes were noticed in the metacarpophalanges, and the first and second phalanges of the second to the fifth hand fingers (Figure 3) and diffuse demineralization with periostal reaction and secondary arthrosis of the tarso-metatarsal bones (Figure 4). Moreover, hand ultrasound examination of feet (August 2014) (Figure 5, Figure 6) shows cortical neregularities in the perimalleolar region bilaterally and synovial effusion in the knees, tarsal and metatarsal joints.

Clinical and radiological changes were considered to be features of primary hypertrophic osteoarthropathy (also known as pachydermoperiostitis). For differential diagnosis acromegalia and gigantism were taken into consideration, and excluded after full endocrinological evaluation (normal head CT, normal serum levels of cortisol,TSH, testosterone, IGF-1 and GH). The patient had no abnormal respiratory, cardiovascular or gastrointestinal symptoms. Still, several other tests were performed to exclude secondary form of hypertrophic osteoarthropathy: heart echocardiography, lung computerized tomography, blood smear.

Although PPD has limited evolution, in our case hand and feet enlargement continues with physical and psychological impact on the patient's daily living. As we would have expected, none on the JIA treatments (DMARDsor biological therapy) influence the PPD's evolution.

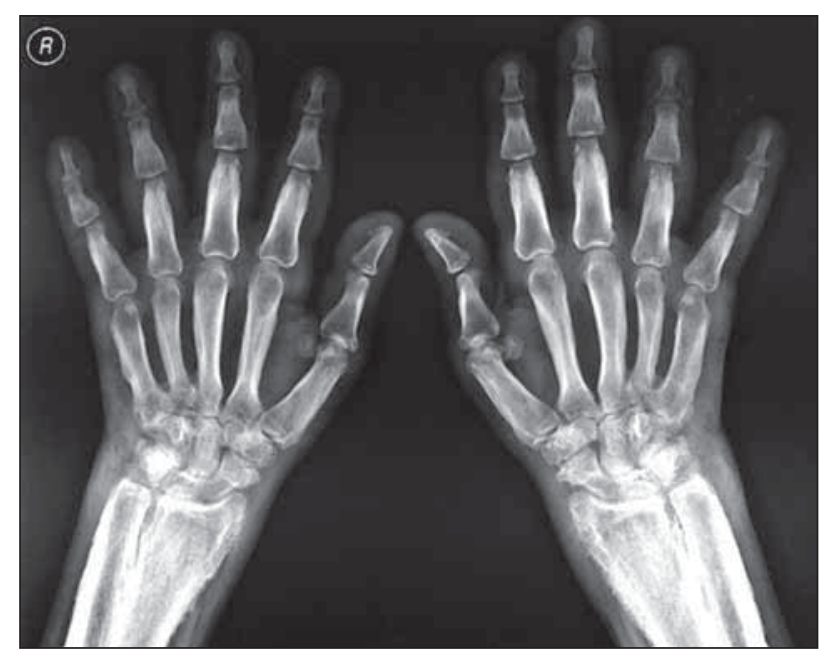

FIGURE 3. Hand x-Ray

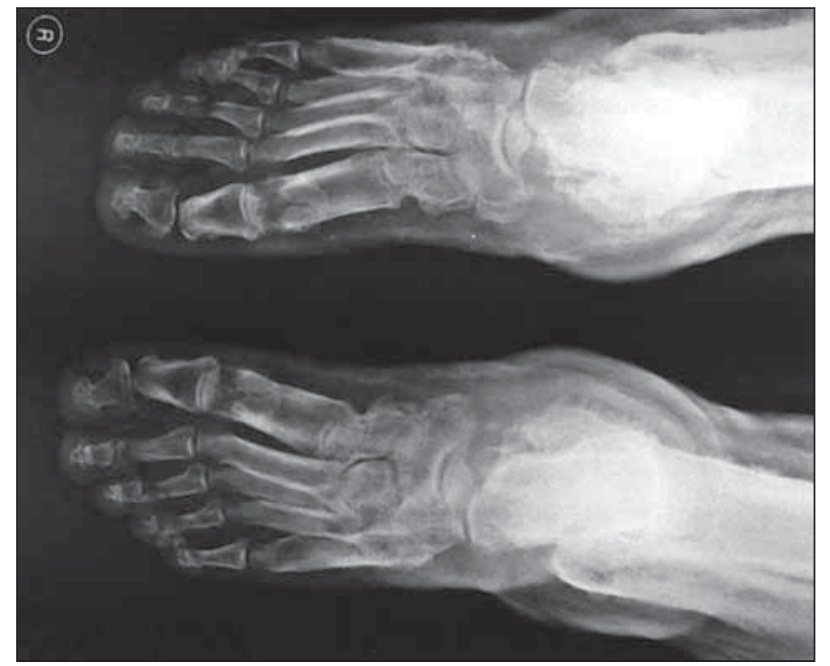

FIGURE 4. Foot $x$-Ray 


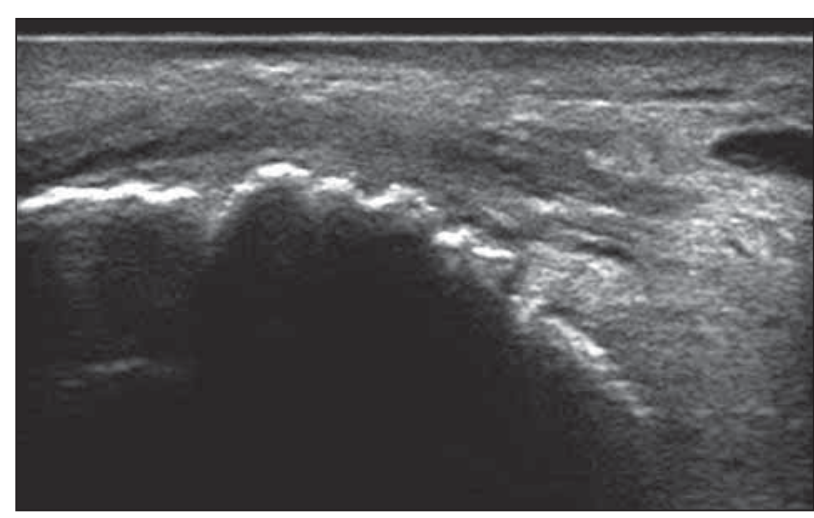

FIGURE 5. Ultrasound of the ankle - malleolar irregularities

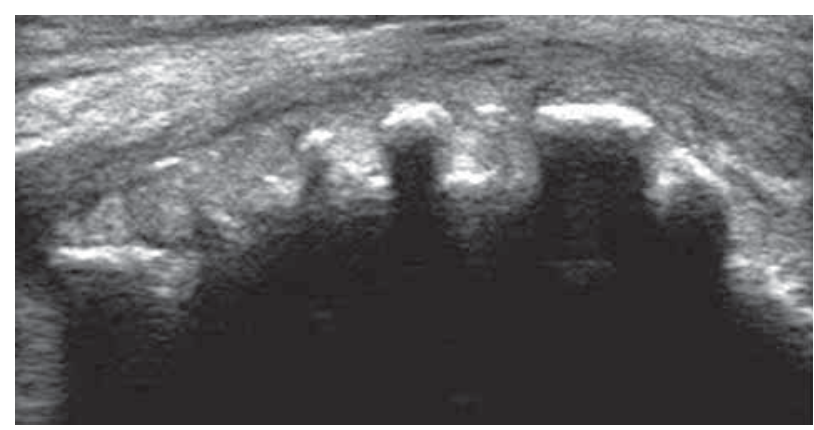

FIGURE 6. Ultrasound of the ankle - malleolar irregularities
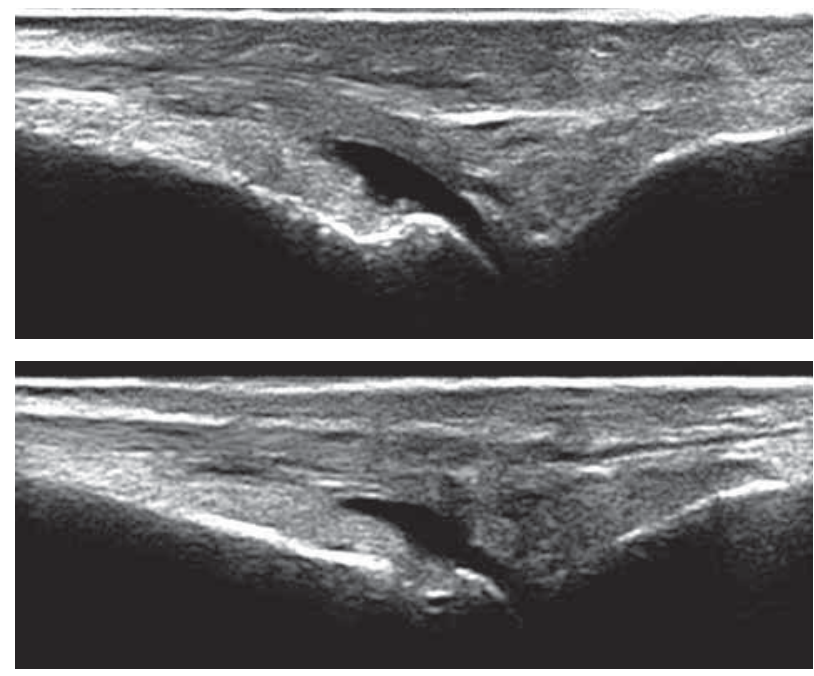

FIGURE 7. Ultrasound of the foot - joint effusion

\section{DISCUSSION}

Pachydermoperiostosis is a rare genetic disorder characterized by skin (thickening, seborrheic dermatitis, cutis gyrata), bone (thickening, clubbing of the fingers) and nail (curved nails) involvement. The male/female ratio favors the male sex, with childhood/adolescence onset and a self-limited evolution. This disorder can be associated with JIA and other rheumatic and non-rheumatic diseases. Our case presents a young male with JIA, currently under treatment with Etanercept that also presents with pachydermoperiostosis, with the illustration of the clinical, radiologic and ultrasound features.

PDP was classified by Touraine et al (2) in 3 subtypes: the complete associated to pachyderma and periostosis, the incomplete form with bone abnormalities and absence of pachyderma, and a fruste form characterized by thickened dermis and minimal to absent bone involvement.

\section{Pathophysiology}

PDP is associated with 15-hydroxyprostaglandin dehydrogenize (HPGD) gene mutations which encodes 15 HPGD, resulting in a persistent elevation of circulating PGE (2) levels (3). Also a deficiency of SLCO2A1, a prostaglandin transporter, is described as the primary cause of pathology (4). Some data focus on the increased levels of IL6 and receptor activator of nuclear factor-kappaB ligand (RANKL) during diseases activity (5).

\section{Clinical presentation}

At the clinical overview skin, hear and finger nail involvement is observed including: scleroderma-like thickening of facial skin, leonine facies with hair over the cheek bones and forehead, cutis vercitis gyrata, seborrheic dermatitis involving the face and scalp, hand and foot hyperkeratosis, bilateral blepharoptosis, facial acne, clubbing, findings also observed in our patients.

Given the physical abnormalities PDP produces, it is important to exclude diseases as acromegaly, thyroid acropachy or syphilitic periostosis.

Numerous case reports of PDP described as clinical manifestations of other diseases: gastrointestinal involvement (6) (gastric carcinoma, Crohn disease, peptic ulcer, chronic gastritis), ginecomastia (7), compressive neuropathy, psoriatic nail involvement (8), congenital heart disease (9), atherotrombotic cerebral infarction (10), osteoporosis (11), rheumatoid arthritis (12), ankilosing spondilitis (13). In some cases, pathologies known to be associated with PDP became clinically active years after PDP onset, recorded cases included Crohn disease, myelofibrosis and congenital heart disease (14). During follow-up, our patient has not developed any symptomatology or signs of cardio-pulmonary disease or neoplastic pathology.

\section{Imaging}

Presence of subperiostal bone formation, especially along the distal tibia, fibula, radius and ulna, 
metacarpophalangs and phalanges is a characteristic of PDP. There have been cases reported with thickening but not narrowing of the spinal canal and enlargement of the paranasal sinuses (16).

\section{CONCLUSION}

Persistence of arthritis and inflammatory syndrome, symmetrical polyarticular involvement and a good response to biological therapy arguments the

\section{REFERENCES}

1. Goyal S., Schwartz R.A., Richards G.M., Goyal R. Pachydermoperiostosis. http://www.emedicine.com. (cited 2006 on).

2. Touraine A., Solente G., Gole L. Un syndrome osteodermopathique: la pachydermie plicaturee avec pachyperiostose ds extremites. Presse Med. 1935; 43:1820-4

3. Uppal S., Diggle C.P., Carr I.M., et al. - Mutations in 15-hydroxyprostaglandin dehydrogenase cause primary hypertrophic osteoarthropathy. Nat Genet. Jun 2008; 40(6):789-93

4. Zhang Z., He J.W., Fu W.Z., Zhang C.Q., Zhang Z.L. Mutations in the SLCO2A1 gene and primary hypertrophic osteoarthropathy: a clinical and biochemical characterization. J Clin Endocrinol Metab. May 2013; 98(5):E923-33

5. Rendina D., De Filippo G., Viceconti R., et al. Interleukin (IL)6 and receptor activator of nuclear factor (NF)-kappaB ligand (RANKL) are increased in the serum of a patient with primary pachydermoperiostosis. Scand J Rheumatol. 2008 May-Jun. 37(3):225-9

6. Ikeda F., Okada H., Mizuno M., et al. Pachydermoperiostosis associated with juvenile polyps of the stomach and gastric adenocarcinoma. J Gastroenterol. 2004; 39(4):370-4

7. Ukinc K., Ersoz H.O., Erem C., et al. Pachydermoperiostosis with gynecomastia and osteoporosis: a rare case with a rare presentation. Int J Clin Pract. Nov 2007; 61(11):1939-40

8. Fietta P., Manganelli P. Pachydermoperiostosis and psoriatic onychopathy: an unusual association. J Eur Acad Dermatol Venereol. Jan 2003; 17(1):73-6 diagnosis of JIA. Hyperhydrosis, periostitis and finger clubbing with the radiological abnormalities raises the suspicion of PDP. As far as we know, few cases have been reported in which both entities PDP and JIA are associated (15), but further research is needed in both diagnosis and monitoring of rheumatological conditions associated to PDP and response to treatment, especially to biological treatment.

9. Levin S.E., Harrisberg J.R., Govendrageloo K. Familial primary hypertrophic osteoarthropathy in association with congenital cardiac disease. Cardiol Young. May 2002; 12(3):304-7

10. Nakajima M., Hirano T., Itoh K., et al. Atherothrombotic brain infarction in a patient with pachydermoperiostosis. Mod Rheumatol. 2008; 18(3):281-4

11. Ukinc K., Ersoz H.O., Erem C., et al. Pachydermoperiostosis with gynecomastia and osteoporosis: a rare case with a rare presentation. Int J Clin Pract. Nov 2007; 61(11):1939-40

12. Diamond S., Momeni M. Primary hypertrophic osteoarthropathy in a patient with rheumatoid arthritis. J Clin Rheumatol. Aug 2007; 13(4):242-3

13. Shinjo S.K., Borba E.F., Gonçalves C.R., et al. Ankylosing spondylitis in a patient with primary hypertrophic osteoarthropathy. J Clin Rheumatol. Jun 2007; 13(3):175

14. Martinez-Lavin M., Vargas A., Rivera-Vinas M. Hypertrophic osteoarthropathy: a palindrome with a pathogenic connotation. Curr Opin Rheumatol. Jan 2008; 20(1):88-91

15. Diamond S., Momeni M. Primary hypertrophic osteoarthropathy in a patient with rheumatoid arthritis. J Clin Rheumatol. 2007 Aug. 13(4):242-3.a

16. Jajic Z., Jajic I., Nemcic T. Primary hypertrophic osteoarthropathy: clinical, radiologic, and scintigraphic characteristics. Arch Med Res. Mar-Apr 2001; 32(2):136-42 